\title{
A Research on use of Robotics in Mining Industry
}

\author{
Ashutosh Kumar Singh, Shahzad Ali
}

\begin{abstract}
Robotics and also the growth in robot use's progress have increased the demand on the list of goals which can be the type of robots, process preparation of robots, functionality assessment and cycle period estimation, for keyboard simulation of robots. For exploration natural surroundings underground mining and the open cast need badly use of robotics. In profound mining, the column and room or board and pillar procedure spreads across the seam, whereas columns and wood will be leaving status to encourage both the mine roof and also exceptionally outfitted machineries used-to retain basic protection and reduce the individual exercise, it's quite much crucial to embrace autonomous technology from subterranean stone. It's demonstrated that robots will soon likely probably do tasks for example moving following beating to stabilize a mine roof, placing explosives or mining from most locations. This paper emphasizes uses and the demand of software from the mining marketplace atmosphere.
\end{abstract}

\section{INTRODUCTION}

Robotics and also the rise in robot use's progress have increased the demand on the list of goals which can be the type of robots, process preparation of robots, functionality assessment and cycle period estimation, for keyboard simulation of robots. Whilst the suitable mapping of every mining surgeries requires some exceptional attention so as to cut the possibility of any sort of injuries, an endeavor was initiated to hold out the endeavor without the human intervention working with the most recent advancements within the area of robotics, assisted with all the domain special info. The advice would be striving to be all accumulated and examined for estimating the degree of danger prevailing at any certain point of time's condition. This surgery is predicted to greatly aid the mine government remain ready with of the current potential rescue actions [1]. What's more, the absence of comprehension concerning the biological ethics and status of the mine restrict recovery and rescue attempts. Technologies provides substantial capability by minimizing exposures to enhance the position of their rescue employees. The mine can be explored by A vehicle and offer the organizations with info that is invaluable to help in executing and planning rescue and search surgeries $[2,3,4]$.Toward simplifying the production procedures, industrial robots are built a substantial donation. The usage of robots exhibits solution or service quality advancement, manufacturing charge decrease, and productiveness improve. Most robots in use to perform uncomplicated repetitive tasks, such as for example for instance pick-and-place, device loading and spray painting

Revised Version Manuscript Received on 10 September, 2019.

Ashutosh Kumar Singh, Electronics and Communication Engineering, Noida Institute of Engineering and Technology, Noida, Uttar Pradesh, India. (Email: research.paper@niet.co.in)

Shahzad Ali, Mechanical Engineering, Noida Institute of Engineering and Technology, Noida, Uttar Pradesh, India.(Email: research.paper@niet.co.in) and area welding. A fundamental approach was supposed because of their operation of the robot's analyzing. It's been found that works very nicely below these states proven in the mining excavation sites' assumptions. The modern fatality stats for the underground and open cast mining surgeries worldwide purpose out the most acute threats to these employees are out of distinct mining requirements notably from your inaccessible regions of the mines exactly wherever by routine systematic observation and upkeep surgeries are hard and thus, not one of those surgeries aren't carried from a systematic foundation. It's correct that there's not any management of those operators about such occurrences [5, 1].Back in general open cast and underground mining requirements certainly really are a company of also the personnel along with strong equipment who function it When mining gear can possibly be automatic to operate devoid of the staff complete care, the mining market can enrich productivity, accessibility mineral pits, also reduce vulnerability. The missing connection would be equipment's power to gauge its own location. The shortage of maps of mines that are underground pose a hazard. As per a new analysis [6], tens of thousands of tens of thousands, possibly tens of thousands of tens of thousands of mines exist inside the States. Perhaps not the U.S. Bureau of Mines understands the specific amount, but as national record of mining statements wasn't mandatory till $1976 . \quad$ Functioning requirements and access channels that are hard to imply that mapping and mining of abandoned mines could possibly be considering described as a feasible choice. It's currently vital to executed devices, To take care of the surroundings protection. This newspaper emphasizes uses and that the demand of use from the mining market.

\section{APPLICATIONS}

Robots will probably do tasks including soon right immediately following beating to stabilize a mine roof moving placing explosives or mining from most locations at which it's not possible for people to perform and live [7].

Cases of this tendency of mining automation Include Things like:

Automatic and tele-operated load-haul-dump trucks which drain the Partitions Even the world's greatest robot Drag-line comprising unloading and loading A robot apparatus for both bolting mine roofs afterwards hammering to stabilize them and drilling By which operators Find It Impossible to move A pilot system to get to mine from bombarded gravels and ponds underground For causing A drilling and hammering apparatus controlled welding. Thus autonomous systems have been useful to keep up with that the security and improving

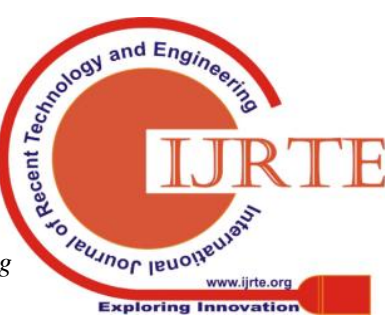




\section{A Research on use of Robotics in Mining Industry}

the manufacturing power as additional quantity of individual power and top machineries can be properly used. Equipment automation could be the spot in mines.

Mining devices have been distinguished by a number of joints or electrically run aspects. Quite a few tasks take a human operator to manually organize with the motion of a number of machine connections by simultaneous constraint of multiple joysticks or alternative control apparatus, Robotics utilized from the producing marketplace may perhaps not be properly utilized for its aid of mining machines procedures for three different causes: the sophistication of mining surgeries, variability of these activities, and also the shifting environment which are metering and require alteration throughout performance. Fig.2. Shows controller structure in mining gear [8] 's cube structure. Its materials were strutting demonstrating how mines into this long run will do the job. That's been automatic to reverse millions of tonnes of rubble and rock's work into a performance requiring 80 percent significantly much less operator participation [9].This monster, that will devour one hundred twenty tonnes of stone has been fitted to take out judgment and the strain required with an individual operator glancing load and when managing its flourish. Even the drag-line was employed to demo the position that robotics can engage in in mining surgeries.

Its materials were strutting demonstrating how mines into this long run will do the job. That's been automatic to reverse millions of tonnes of rubble and rock's work into a performance requiring 80 percent significantly much less operator participation [9].

\section{USAGE IN UNDERGROUND MINES}

As a result of safety intention in colonies, the dependence on robotics is extremely important. The followings are high lights the part of use in subterranean plantations.Mine navigation or communicating with roboticsRanking estimation Equipment automation Mine Difficulties

The state-run Korea Coal Corp. (KOCOAL) [10] signed a memorandum of understanding (MOU) together with about 3 Korean technology associations and employers, like the Korea Institute of Machinery \& resources, for that evolution of clever coalmining robots at today's science intricate from Daejeon[11]. The robots are not going to drill but may upward - and - shake coal on a conveyor for transport out to restrain them liberally with a speaker. Productivity will be raised by the debut of mining robots. The robots increase productivity by operating across the clock and moving deeper, in the event the job will be accomplished, and this will cut the possibility of declines against mining, robots that are smart will probably likely to be placed to function following half an hour of test surgery at 2013[12].

\section{CHALLENGES\& RESULTS}

Demands are imposed by the mine natural surroundings. Utilizing reckoning is eliminated as of this irregular outermost layer of the mine corridor ground, this mine machine's moves, also the sum of slippage of this machine's paths. Due to the fact errors in the your gyro drift transcend acceptable grades, functioning of mine products precludes using an INS[13]. It's desired to do the job at just shortened areas without having initially setup the essential beacons (specially in the event the mapping has been done mechanically in combination with all the positioning estimation)[14]. Considering that the atmosphere will be littered with people and machines perhaps maybe not a range of beacons can possibly be occluded. Hence beacons aren't workable at a subterranean mine atmosphere. Since mining devices is more portable, a location estimator that is appropriate has to possess a cycle period. Even the movement of mining devices and also the fated that is poor preclude location quotes by ways[15].

\section{CONCLUSION}

This paper emphasizes the value of platform in the mining market. Some system discussed and also the requirement of the machine in mine has been pointed out. Though not many works are achieved inside this region but the researcher's job will last, the requirement of the autonomous system has been just emphasized and becoming reasoned it is critical to embrace a robotic technique from subterranean mines to decrease the human energy and improving protection.

\section{REFERENCES}

1. L. Fortunati, A. Esposito, and G. Lugano, "Introduction to the Special Issue "Beyond Industrial Robotics: Social Robots Entering Public and Domestic Spheres\{"'\}," Inf. Soc., vol. 31, no. 3, SI, pp. 229-236, May 2015.

2. G. Zhang et al., "Biomedical Applications of Capsule and Rehabilitation Robots Current development in biomedical capsule micro-robots and therapy rehabilitation robots," in 2015 INTERNATIONAL CONFERENCE ON MANIPULATION, MANUFACTURING AND MEASUREMENT ON THE NANOSCALE (3M-NANO), 2015, pp. 7-11.

3. S. A. Applin and M. D. Fischer, "New Technologies and Mixed-Use Convergence How Humans and Algorithms are Adapting to Each Other," in 2015 IEEE INTERNATIONAL SYMPOSIUM ON TECHNOLOGY AND SOCIETY (ISTAS), 2015.

4. E. J. Pekkeriet, E. J. van Henten, and J. B. Campen, "Contribution of Innovative Technologies to New Developments in Horticulture," in II INTERNATIONAL SYMPOSIUM ON HORTICULTURE IN EUROPE, 2015, vol. 1099 , pp. 45-54.

5. A. Muxfeldt, D. Kubus, and F. M. Wahl, "Developing New Application Fields for Industrial Robots - Four Examples for Academia-Industry Collaboration," in PROCEEDINGS OF 2015 IEEE 20TH CONFERENCE ON EMERGING TECHNOLOGIES \& FACTORY AUTOMATION (ETFA), 2015.

6. J. M. Abe, S. Akama, and K. Nakamatsu, "Applications," in INTRODUCTION TO ANNOTATED LOGICS: FOUNDATIONS FOR PARACOMPLETE AND PARACONSISTENT REASONING, vol. 88, 2015, pp. 111-173.

7. A. Albert-Baskar, H. Lee, J.-M. Park, J.-H. Baek, and E. $\mathrm{Ji}$, "Use of High-Throughput Trypsin Digestion in Proteomic Studies," Curr. Proteomics, vol. 12, no. 4, pp. 210-216, 2015. 
8. J. Ogbemhe and K. Mpofu, "Towards achieving a fully intelligent robotic arc welding: a review," Ind. Robot. Int. J. Robot. Res. Appl., vol. 42, no. 5, pp. 475-484, 2015.

9. R. Li, W. Wu, and H. Qiao, "The compliance of robotic hands - from functionality to mechanism," Assem. Autom., vol. 35, no. 3, pp. 281-286, 2015.

10. J. Pransky, "The Pransky interview: DrEsbenOstergaard, inventor, co-founder and CTO of Universal Robots," Ind. Robot. Int. J. Robot. Res. Appl., vol. 42, no. 2, pp. 93-97, 2015.

11. C. Finetto, G. Rosati, M. Faccio, and A. Rossi, "Implementation framework for a fully flexible assembly system (F-FAS)," Assem. Autom., vol. 35, no. 1, SI, pp. 114-121, 2015.

12. R. Vidoni, M. Bietresato, A. Gasparetto, and F. Mazzetto, "Evaluation and stability comparison of different vehicle configurations for robotic agricultural operations on side-slopes," Biosyst. Eng., vol. 129, pp. 197-211, Jan. 2015.

13. P. D. Dantonio et al., "Comparative evaluation of newborn bloodspot specimen cards by experienced laboratory personnel and by an optical scanning instrument," Mol. Genet. Metab., vol. 113, no. 1-2, SI, pp. 62-66, 2014.

14. M. Shurrab, R. Schilling, E. Gang, E. M. Khan, and E. Crystal, "Robotics in invasive cardiac electrophysiology," Expert Rev. Med. Devices, vol. 11, no. 4, pp. 375-381, Jul. 2014.

15. J. Y. C. Chen and M. J. Barnes, "Human-Agent Teaming for Multirobot Control: A Review of Human Factors Issues," IEEE Trans. HUMAN-MACHINE Syst., vol. 44, no. 1, pp. 13-29, Feb. 2014. 